\section{Posttraumatic growth in adolescent survivors of earthquake, tsunami, and liquefaction in Palu Indonesia: a phenomenological study}

\author{
Siti Hajar Salawali, ${ }^{1}$ Herni Susanti, ${ }^{1}$ \\ Novy Helena Catharina Daulima, ${ }^{1}$ \\ Arcellia Farosyah Putri2
}

1 Faculty of Nursing, Universitas Indonesia; 2Indonesian Emergency and Disaster Nurses Association, Indonesia

\begin{abstract}
Exploration of posttraumatic growth (PTG) experiences in adolescent survivors of earthquakes, tsunamis, or liquefaction are needed by nurses to maximize the potential for recovery and growth of adolescents from trauma after natural disasters. The study used a qualitative method with a descriptive phenomenology approach. Data were collected through in-depth interviews with 16 adolescent survivors and were analyzed using the Colaizzi method. The results of this study have two main themes: trauma becoming the basis for realizing the meaning of life and escaping from disaster as a second chance to live better. PTG is a positive change that needs to be pursued. Escaping from disaster and realizing the meaning of life are the key points to get success in pursuing PTG to live a better life. In addition, support from mental health nurses through cognitive therapy (CT) and acceptance commitment therapy (ACT) are needed to increase the PTG.
\end{abstract}

\section{Introduction}

Disasters occur every day around the world causing tremendous effects like death, physical and psychological injury, and damaged facilities. This condition affects the health system, health care, social, and economic functions. Indonesia is in the fourth rank after China, India, and the Philippines, ${ }^{1}$ and earthquakes are the biggest disaster that has claimed 3600 lives compared to other natural disasters. ${ }^{2}$ Earthquakes that occur are usually accompanied by dangerous secondary effects, such as tsunamis and liquefaction. ${ }^{3}$

Adolescents are individuals who are more stressed and traumatized when a disaster occurs compared to adults and children, and this condition can be influenced by the stages of development of adoles- cence and psychological factors. ${ }^{4}$ During a disaster period, adolescents also tend to be ignored and used as passive victims. This is because adolescents are among vulnerable groups of children and adults. This situation makes people tend to ignore the needs of adolescents, and that causes the failure to focus on adolescents in terms of disaster preparedness or recovery activities after a disaster. ${ }^{5}$

The data show that adolescents often suffer from traumatic events with the prevalence of trauma exposure reaching up to $65 \%,{ }^{6}$ but in a preliminary study that has been done in adolescent survivors of the earthquake and tsunami in Palu Indonesia in 2018, they showed positive growth even before 6 months after the disaster. Positive growth experienced by individuals after they face a traumatic event is a result of efforts to overcome the psychological consequences that arise from trauma, and this can be seen in 5 domains; appreciation of life, new possibilities, relating to others, personal strength, and spiritual change. ${ }^{7}$ Posttraumatic growth can occur in adolescents who experience a variety of traumas, including traumas caused by natural disasters. ${ }^{8}$ However, different types of disasters, the use of participants who do not live at the disaster site, and culture may lead to differences in PTG.

In Indonesia, PTG has been studied in adult participants with backgrounds of illness-related traumatic events, ${ }^{9}$ in individuals where one of the parents has died, 10 and in a victim of domestic violence. ${ }^{11}$ PTG studies that investigate adolescents who survived natural disasters either in earthquakes, tsunamis, or liquefaction have not been found. Indonesia is known as the ring of fire where earthquakes are experienced almost every time, and $80 \%$ of earthquakes in the world occur along the ring of fire. ${ }^{2}$

The earthquake that occurred in Palu City was not a single event, as it triggered a tsunami and liquefaction. Sulawesi is an island that has many faults that have the potential to cause earthquakes, one of which is the Palu Koro fault, making Eastern Indonesia have twice the potential of earthquake disaster compared to Western Indonesia. ${ }^{12}$ With these conditions, it is interesting to study PTG that occurred for less than six months in adolescents who survived the earthquake, tsunami, or liquefaction in Palu.

\section{Materials and Methods}

This study is a qualitative study that uses a descriptive phenomenology approach and is used to look at an overview of PTG
Correspondence: Herni Susanti, Department of Mental Health Nursing, Faculty of Nursing, Universitas Indonesia, Jalan Prof. Dr. Bahder Djohan, Kampus UI Depok, West Java, 16424 Indonesia.

Tel.: +6221.78849120 - Fax: +6221.7864124.

E-mail: herni-s@ui.ac.id

Key words: Posttraumatic growth (PTG); adolescent survivors; earthquake; tsunami; liquefaction.

Acknowledgments: The authors would like to express their gratitude to the enumerators who were involved in this study.

Funding: This study was supported by Hibah PITTA B 2019, funded by DRPM Universitas Indonesia (No. NKB-0492/UN2.R3.1/HKP.05. 00/2019).

Contributions: SHS substantial contributions to the conception of the work; acquisition, analysis, or interpretation of data for the work. HS, NHCD, and AFP supervised the findings of this work; final approval of the version to be published. All authors discussed the results and contributed to the final manuscript.

Ethical approval: The study used distress management guidelines during interviews and obtained ethical approval from the Research Ethics Committee of the Faculty of Nursing, Universitas Indonesia (No. 35/UN2.F12.D1/ PDP.04.02/2019).

This work is licensed under a Creative Commons Attribution NonCommercial 4.0 License (CC BY-NC 4.0).

(C) Copyright: the Author(s), 2020

Licensee PAGEPress, Italy

Pediatric Reports 2020; 12(s1):8699

doi:10.4081/pr.2020.8699

experience in adolescent survivors who have survived natural earthquakes, tsunamis, or liquefaction. The descriptive phenomenology approach is used precisely to obtain data by exploring one's experience from a first-person perspective. In addition, for the first time, the phenomenology of PTG in adolescent survivors of natural disasters was investigated in Indonesia.

Participants in this study were adolescents who experienced PTG after natural disasters that occurred in Palu, Central Sulawesi, in September 2018. The sample was selected using a purposive sampling technique with the following inclusion criteria; i) adolescents aged 12-18 years; ii) survivors of earthquake, tsunami, or liquefaction; iii) a resident in a disaster area; and iv) having a minimum score of 3 (of a total 
score of 6) on at least one of the Posttraumatic Growth Inventory for Children (PTGI-CR) domains based on the PTGI-CR instrument. 13 The study used distress management guidelines during interviews and obtained ethical approval from the Research Ethics Committee of the Faculty of Nursing, Universitas Indonesia No. 35/UN2.F12.D1/PDP.04.02/2019.

Data were collected through in-depth interviews using field notes. The researcher asked permission from the parents/guardians of the adolescent when the researcher wanted to meet them. ${ }^{14}$ The researchers then met with the adolescents and distributed PTGI-CR instruments (4th criterion). The researcher explained the purpose and benefits of the study and guaranteed the confidentiality of the identity of adolescent survivors who fulfilled the inclusion criteria. Adolescents who met all the inclusion criteria and were willing to participate had been informed about the purpose and benefit of this research. Their anonymity and confidentiality were guaranteed by the researcher, and they signed the informed consent form. The interview was carried out at the participants' house, temporary shelters, mosques, and coastal areas of the tsunami disaster. The number of participants involved in this study was 16 adolescents with a duration of the interview of about 30-60 minutes for each participant.

Data were analyzed using Colaizzi (1978). ${ }^{15}$ The validity of the data in this study consists of credibility by validating the results for each participant and continued with the analysis of Colaizzi. During the study, the researcher performed reflexivity as a process of introspection on the role of subjectivity in research on the values and assumptions of researchers that could influence this research. Transferability was conducted by describing in a clear and systematic manner the details related to the experience conveyed by participants by entering the note field in the quotation. The involvement of the supervisor in giving input about the results of the interview until data analysis is a way of maintaining dependability of this study, while confirmation is obtained by direct observation during the interview process, and this confirms to the participants that the results of data analysis are in accordance with what was conveyed by the participants.

\section{Results}

Each participant was given a code to illustrate the research sequence number. The code used P1 to P16 in the order in which the interview was conducted. Sixteen adolescent survivors were involved in the study. The youngest was 14 years old, and the oldest was 18 years old. The majority of them are female and Muslim. Most of them are survivors of the earthquake and tsunami, with the highest total PTG score being 28 and the lowest score being 18 (Table 1).

\section{Theme 1. Trauma is the basis for realizing the meaning of life}

This theme consists of 3 categories. The first category in this study found interesting things, where all teenagers make traumatic experiences to become initial changes, illustrated from the following statements:

"... with this disaster, I greatly changed my self $(P 1,31)$ ”.

"... because of this incident, I want to change the fact because of this incident (P6, 30)".

Trauma is also used as an alarm or reminder for adolescents in their lives to do better and leave bad behavior as the second category, which is presented below:

"... I used to argue with my parents (blushing), but now if I remembered yesterday, God would warn me again (forehead slightly wrinkled), so just do better than before, don't make the same mistakes as before! (P8, 49)".

The disaster trauma experienced by adolescents in this study also made them realize the meaning of life, which became the third category. Some of the meanings of adolescents' life are realized as life in this world to be able to help parents and seek God's blessing, which is conveyed as follows:

“... I never did my laundry, only my parents often washed my clothes and I realized, why do I live in this world without helping my parents...(P1, 53)".

“... I was lazy. After that incident, I got guidance to be better. I used niqab (veil). Honestly, there are a lot of difficulties. Some people say don't be such a saint, and hypocrite. But I'm still patient because we live solely looking for the pleasure of God, not human. From all of this, I learned (P2, 25)".

Table 1. Characteristics of adolescent survivors $(\mathrm{N}=16)$.

\begin{tabular}{|c|c|c|c|c|c|c|c|c|c|c|c|}
\hline Code & Age & Gender & Education/Class & Religion & Types of Disaster & & Sco & of 51 & Dor & & \\
\hline Participant & & & & & & ROa & ALb & PSc & NPd & SCe & Totalf \\
\hline P1 & 17 & Female & SMAXI & Islam & Earthquake \& Tsunami & 6 & 6 & 5 & 5 & 6 & 28 \\
\hline P2 & 16 & Female & SMAX & Islam & Earthquake \& Tsunami & 5 & 5 & 5 & 5 & 6 & 26 \\
\hline P3 & 18 & Male & SMA/XII & Islam & Earthquake \& Liquefaction & 6 & 4 & 2 & 2 & 6 & 20 \\
\hline P4 & 18 & Male & SMAXII & Islam & Earthquake \& Tsunami & 5 & 5 & 2 & 4 & 6 & 22 \\
\hline P5 & 18 & Female & SMAXII & Islam & Earthquake \& Tsunami & 5 & 5 & 4 & 6 & 6 & 26 \\
\hline P6 & 16 & Male & SMAXI & Islam & Earthquake \& Tsunami & 5 & 5 & 4 & 3 & 5 & 22 \\
\hline P7 & 16 & Female & SMAXI & Islam & Earthquake & 5 & 6 & 6 & 6 & 6 & 29 \\
\hline P8 & 16 & Female & SMAXI & Islam & Earthquake \& Tsunami & 3 & 3 & 3 & 3 & 6 & 18 \\
\hline P9 & 16 & Female & SMAXI & Islam & Earthquake & 4 & 5 & 4 & 6 & 6 & 25 \\
\hline P10 & 16 & Female & SMA/XI & Islam & Earthquake \& Tsunami & 5 & 4 & 2 & 4 & 5 & 20 \\
\hline P11 & 16 & Female & SMAXI & Islam & Earthquake \& Tsunami & 6 & 6 & 5 & 4 & 5 & 26 \\
\hline P12 & 16 & Female & SMAXI & Chatolic & Earthquake & 6 & 6 & 5 & 4 & 6 & 27 \\
\hline P13 & 17 & Female & SMAXII & Islam & Earthquake \& Tsunami & 6 & 6 & 5 & 3 & 3 & 23 \\
\hline P14 & 15 & Female & SMAX & Islam & Earthquake \& Tsunami & 5 & 4 & 4 & 3 & 5 & 21 \\
\hline P15 & 16 & Female & SMAXI & Islam & Earthquake & 5 & 5 & 3 & 5 & 5 & 23 \\
\hline P16 & 14 & Female & SMPNIII & Islam & Earthquake \& Tsunami & 4 & 4 & 2 & 3 & 5 & 18 \\
\hline
\end{tabular}

aRelating to Others (2 items); bAppreciation of Life (2 items); cPersonal Strength (2 items); dNew Possibilities (2 items); eSpiritual Change (2 items); and fTotal Score (10 items=30). 
Interestingly, some adolescents interpret the meaning of life to set up charities for a more enduring life after death, as illustrated in the following statement:

"...trying to be someone who has a purpose in life...(radiant facial expressions). So live to die, we must prepare when we live in this world. When we are gone, others can remember, and we are ready to go $($ P12, 102)".

“... during yesterday's incident, death was always in my mind (teary eyes)...So as much as possible, we do better. Have a purpose in life by to set up charities for eternal life in the hereafter $(P 9,79)$ '.

\section{Theme 2. Survive from disaster as a second chance to live better}

Various kinds of losses were experienced by adolescents, starting with a loss of loved ones, the loss of a home as a place of residence from birth until they grew up, which certainly provides a beautiful memory in his/her time. When a disaster strikes adolescents, they also experience physical trauma where they have to endure pain. They are willing to stay hungry because when they remember the separation from their family, such as their sister or their parents, which makes them suffer, it makes them lose their appetite. However, these experiences make adolescents struggle to survive. Apart from the devastating disaster and the struggle that must be overcome, the adolescents interpret the condition as a gift given by God.

This theme consists of 2 categories; being given a second opportunity is the first category, as illustrated in the phrase below:

"... God has given me a second time (teary eyes) if without Him, I might have nothing $(P 2,13)$ ".

“... God still gives me a chance to live, to be a better person (voice trembles) $(P 9,82)$ )".

The second chance for life given by God will not be meaningful if not utilized as well as possible. The opportunity to live well becomes the second category in this theme. The adolescents use it to live well, starting with stopping any bad behavior and committing to change, as follows:

“... I think, before this disaster, I was a bad person, rarely praying, I continued to smoke even though I was scolded. Now, I want to change (smiles, laughs a little because of shyness) $(P 3,22) "$.

Furthermore, adolescents value time and do not delay work, which is expressed as follows:

“... I also appreciate the time... I used to just play, play cellphones, now I help my mother to cook or clean the house (P10, 66)"

Taking advantage of opportunities is also carried out by adolescents with no despair as they try to do things that have never been done before and reaching aspirations, the adolescents revealed:

"... I never do before, I never imagined that I would stand there (telling me when he was standing at a red light, holding a box to ask for donations for victims of the Sunda Strait disaster and for his friend whose house was on fire), but when doing that, like very happy,... we do things that have never been done before (beaming faces, smile happily) (P12, 94)".

The most interesting thing of this study is the fact that all adolescents use it by increasing their self quality to God and serving their parents by not arguing, appreciating, obeying, and not hurting their hearts, which is expressed as follows:

"... yesterday my prayers were rather hollow. Alhamdulillah, now I am diligent, more able to give alms, recite, get closer to Allah (smile, happiness radiates from his eyes) (P5, 85)",

"... as much as possible, we do not hurt our mother. We must be filial $(P 9,114)$ ”.

Helping parents is also done by adolescents by looking for firewood and by working to get money for parents, as follows:

"... my father is no longer working (because of disaster). So where I get money, moreover, we still live in this shelter as there is no house yet. So I'm also looking to get money by selling cakes $(P 13,24)$ ".

Adolescents say that the opportunity was also used by spending more time at home with family, described as follows:

"... I have started to be closer to my sister too, because I have often been together $(P 4,40) "$

The adolescents also live by doing a lot of kindness, solving problems better, and being more independent in living their lives, as follows:

"... because I want to be better with care to others (P5, 64)”.

"... now I can solve it (problems) by myself... I think I am more independent $(P 11,43)$ '”.

Changes not only happen in their lives, but they invite others to change, illustrated from the following statement:

"... at school, they don't pray, I say," let's pray, don't you remember yesterday's earthquake? (Soft in conveying, eyes look warm, smiling happily) $(P 15,15)$ “.

\section{Discussion}

\section{Trauma is the basis for realizing the meaning of life}

Posttraumatic growth is an experience of psychological change towards a positive change as a result of individual struggles in dealing with very challenging traumatic events for adolescents. 16 They interpret disaster trauma as the starting point to make a change and realize the meaning of life. They also make trauma an alarm to continue to do good things and not to go back to their condition before the disaster. Some adolescents talked quite emotionally. The research by Mancini et al. states that trauma can be a cause of psychological improvement in survivors, and the rise of unpleasant emotional experiences can lead to selfreflection and determination to overcome the problems experienced. ${ }^{17}$ This implies that the emotional experience one has can affect one's motivation to get out and grow from the condition.

Adolescents also make trauma as a way of realizing the true meaning of life. The process of realizing the meaning of life certainly involves cognitive processes. Traumatic experiences can make individuals change in cognitive involvement or commonly referred to as rumination, immediately after trauma. ${ }^{18}$ Rumination is a recurring thought of the traumatic event experienced. 8 Tedeschi and Calhoun said that PTG would emerge during the deliberation process, which is deliberated intentionally by individuals where the content of cognitive processes carries out an attempt to improve, restructure, and rebuild the individual's way of thinking, interpreting, and understanding the world at the same time. Individuals try to see the trauma as a reason that makes sense. ${ }^{16}$

The deliberate rumination process is seen in adolescents. Adolescents realize the meaning of their lives by doing good to their parents and seeking God's blessing. There are even adolescents who prepare charities to live more eternally after death. They said that after the disaster occurred, the shadow of death was always in their mind. It made them realize that death would come at any time. Thus, they needed to prepare for life after death. Belief in death affects their daily lives and choices. Previous studies revealed that a meaningful life was found to correlate with positive change and was predicted to significantly increase the PTG score, ${ }^{19}$ and this was in accordance with the results of the research obtained by researchers. The new possibility of meaningfulness found by individuals when struggling to overcome trauma is then 
the potential to become PTG in individuals. ${ }^{16}$ Parents, seeking God's blessing, and preparing charity for more eternal life are the meanings of life for adolescent survivors and are considered to be the key to success in this research to grow PTG.

However, there is a tendency in some people that the rumination process is more intrusive than deliberate. ${ }^{20}$ This is why, after experiencing a traumatic event, people show a positive and negative direction. People that experienced a traumatic event were not asked to remember the event. This includes whether the individual is able to divert the instrument from intrusive to deliberate. The researcher argues that posttraumatic growth is a positive and active change process. This means that in order to foster positive change, their effort is needed both internally and externally. Longitudinal observational studies show that some survivors can reach PTG without formal interventions. This might be influenced by existing resources in their social environment, and these contribute to the development of PTG. ${ }^{21,22}$

Mental health nurse support is also needed by individuals after experiencing a traumatic event as a form of attention and effort to grow PTG. An individual can achieve meaningfulness after he/she can manage the impact of trauma on his/her psychological condition. Some therapies found in mental health nursing that are considered appropriate are cognitive therapy (CT) and acceptance commitment therapy (ACT). ${ }^{23}$

\section{Survive from traumatic events as a second chance to live better}

Adolescent survivors in this study showed PTG less than 6 months. The results of a study conducted by Stutts and Stanland, and Lechner et al. revealed that how individuals spend their time is more important than the actual time. ${ }^{24}$ This can be seen from how adolescent survivors spend their time living their lives better on the second chance they have. This finding is in line with the results of the research conducted by Furslund that the second life is defined as the return experience of the life of death to real life. This makes them reassess the importance of their lives and live as well as possible because of the gratitude of the second life they have. 25

The participants also expressed their determination to stop having bad behavior, and some of them even have started fixing their bad behavior and trying to make better decisions. Some of the teenagers cried hard when they remembered their mistakes in the past, but behind those cries, there was determination to be better. This illustrated the change of perception and a new understand- ing which will lead to stronger individuals. This is referred to in the first domain of PTG, which is personal strength. ${ }^{26}$ Traumatic events show that every individual is vulnerable to losses and tragedies, but there are many who face the challenge and make themselves stronger and better.

With the change of perception in individuals, it will lead to the second domain which is new possibilities. This is a phase where people start to identify new chances and possibilities after traumatic events. ${ }^{16}$ This could be seen in the adolescents when they started to do new things and achieve their dreams. The adolescents grow by wiping away their tears and putting on a smile, as they are ready to face the world.

In this research, there is a change in terms of relating to others. Individuals will have stronger relationships with other people, especially those who are present during their difficult times. 27 The adolescents expressed that they will be better for their parents and other people. They grow into individuals with a great sense of responsibility and become more mature in facing their problems. Some adolescents expressed that they have a second chance to lead a better life, and as such they put more value in time and do not procrastinate. After traumatic events, people will experience a change of perception where they form a greater appreciation of life and changed sense of priorities. ${ }^{8}$

What is more interesting in this study is the adolescents started becoming closer to God and started to pray more. It shows that a religious factor is also influential in their effort to overcome their trauma. ${ }^{16,28}$ In addition, the adolescents believe that by being close to God, they will be guided and guarded. This refers to spiritual change, which is a change in someone's spiritual aspect and things that are existential.16,23 Even though traumatic events can lead to psychological pressure, it can also give them chances to change and be better. ${ }^{29}$ The change not only occurs among adolescents, but it also affects their family and people in their surroundings.

This research can be seen as a new hope for nurses in an effort to reduce psychosocial problems caused by natural disasters, especially in adolescents. This is because this research proves that adolescents with difficult conditions are able to rise and grow. However, there are several limitations to the study. The limitation of this research lies in the fact that most of the respondents are earthquake and tsunami survivors, and only one of them is a survivor of liquefaction. It is also important to note that at first, the researcher distributed PTG-CR questionnaires to four liquefaction survivors, but they do not experience PTG, which is included in the research criteria.

\section{Conclusions}

An event that happens in life is sometimes unforgettable. Either good or bad, it will always create stressful moments for the experiencer. However, PTG has the ability to make someone who went through traumatic events to become better and change into a more mature and responsible person. Posttraumatic Growth happens only when the experiencer is active and puts effort into their struggle. Surviving from the disaster and realizing the importance and meaning of life are the key factors which show the existence of PTG. Support from mental health nurses through CT and ACT is needed to increase the PTG. As a suggestion, the next researcher can conduct a qualitative or quantitative study on the efficacy of mental nursery therapy in growing PTG.

\section{References}

1. United Nations Economic and Social Commission for Asia and the Pacific \& United Nations International Strategy for Disaster Reduction. Protecting development gains: Reducting disaster vulnerability and building resilience in Asia and the Pacific. Bangkok: UNISDR \& ESCAP; 2010. Available from: https://www.unescap.org/sites/default/fi les/publications/Asia-Pacific-DisasterReport-2010.pdf [Accessed 21st November 2018].

2. Indonesia National Board for Disaster Management. Data informasi bencana Indonesia: Bencana alam di Indonesia tahun 2011 sampai dengan 2018. Available from: http://bnpb.cloud/dibi/ tabel1a [Accessed 21st November 2018].

3. McCall GJH. Tectonics earthquakes. In: Elias S, Alderton DHM, Bliznak V. (eds.) Reference Module in Earth Systems and Environmental Sciences. Amsterdam, Netherlands: Elsevier Inc.; 2013.

4. Chen CV, Chaby LE, Nazeer S, Liberzon I. Effects of trauma in adulthood and adolescence on fear extinction and extinction retention: Advancing animal models of posttraumatic stress disorder. Front Behav Neurosci 2018;12:247.

5. Cahill H, Beadle S, Mitch J, et al. Adolescents in emergencies: A focus on adolescents. Youth Research Centre; 2010. Available from: https://education.unimelb.edu.au/yrc/assets/docs/yrc -misc-docs/adolescents_in_emergencies.pdf 
6. Alisic E, Jongmans MJ, van Wesel F, Kleber RJ. Building child trauma theory from longitudinal studies: A meta-analysis. Clin Psychol Rev 2011;31:736-47.

7. Tedeschi RG, Calhoun LG. The posttraumatic growth inventory: Measuring the positive legacy of trauma. J Trauma Stress 1996; 9:455-71.

8. Cryder CH, Kilmer RP, Tedeschi RG, Calhoun LG. An exploratory study of posttraumatic growth in children following a natural disaster. Am J Orthopsychiatry 2006;76:65-9.

9. Yuhbaba ZN, Winarni I, Lestari R. Studi fenomenologi: Post traumatic growth pada orang tua anak penderita kanker. Jurnal Ilmu Keperawatan 2017;5:81-95.

10. Nataliza A. Intervensi model posstraumatic growth path (PTGP) untuk meningkatkan posttraumatic growth pada individu dewasa muda yang mengalami grieving karena kematian salah satu orang tua. [unpublished thesis]. Depok: Universitas Indonesia; 2013.

11. Uasni ZFAH. Posttraumatic growth pada korban kekerasan dalam rumah tangga. PSIKOBORNEO 2019;7:106-22.

12. Pakpahan S, Ngadmanto D, Masturyono M, et al. Analisis kegempaan di zona sesar Palu Koro, Sulawesi Tengah. Jurnal Lingkungan dan Bencana Geologi 2015;6:253-64.

13. Kilmer RP, Gil-Rivas V, Tedeschi RG, et al. Use of the revised posttraumatic growth inventory for children. J Trauma Stress 2009;22:248-53.

14. Lambert V, Glacken M. Engaging with children in research: Theoretical and practical implications of negotiating informed consent/assent. Nurs Ethics 2011;18:781-801.

15. Wirihana L, Welch A, Williamson M, et al. Using Colaizzi's method of data analysis to explore the experiences of nurse academics teaching on satellite campuses. Nurse Res 2018;25:30-4.

16. Tedeschi RG, Calhoun LG. Posttraumatic growth: Conceptual foundations and empirical evidence. Psychol Inq 2004;15:1-18.

17. Mancini AD, Littleton HL, Grills AE. Can people benefit from acute stress? Social support, psychological improvement, and resilience after the Virginia Tech Campus shootings. Clin Psychol Sci 2015;4:401-17.

18. García FE, Cova F, Rincón P, et al. Coping, rumination and posttraumatic growth in people affected by an earthquake. Psicothema 2016;28:59-65.

19. Linley PA, Joseph S. Meaning in life and posttraumatic growth. J Loss Trauma 2011;16:150-9.

20. Leal-Soto F, Carmona-Halty M, FerrerUrbina R. Rumination in posttraumatic stress and growth after a natural disaster: A model from Northern Chile 2014 Earthquakes. Eur J Psychotraumatol 2016;7:31638.

21. Danhauer SC, Russell G, Case LD, et al. Trajectories of posttraumatic growth and associated characteristics in women with breast cancer. Ann Behav Med 2015;49:650-9.

22. $\mathrm{Xu} \mathrm{W,} \mathrm{Ding} \mathrm{X,} \mathrm{Goh} \mathrm{PH,} \mathrm{An} \mathrm{Y.}$ Dispositional mindfulness moderates the relationship between depression and posttraumatic growth in Chinese adolescents following a tornado. Pers Indiv Dif 2018;127:15-21.

23. Forman EM, Herbert JD, Moitra E, et al. A randomized controlled effectiveness trial of acceptance and commitment therapy and cognitive therapy for anxiety and depression. Behav Modif 2007;31:722-99.

24. Stutts LA, Stanaland AW. Posttraumatic growth in individuals with amputations. Disabil Health J 2016;9:167-71.

25. Forslund AS, Zingmark K, Jansson JH, et al. Meanings of people's lived experiences of surviving an out-of-hospital cardiac arrest, 1 month after the event. J Cardiovasc Nurs 2014;29:464-71.

26. Tedeschi RG, Calhoun LG. Posttraumatic growth. In: H.S. Friedman (Ed.). Encyclopedia of mental health. 2nd ed. Waltham, M.A.: Academic Press; 2016. pp. 305-307.

27. Siqveland J, Hafstad, GS, Tedeschi RG. Posttraumatic growth in parents after a natural disaster. J Loss Trauma 2012; 17:536-44.

28. Brooks M, Lowe M, Graham-Kevan N, Robinson S. Posttraumatic growth in students, crime survivors, and trauma workers exposed to adversity. Pers Indiv Dif 2016;98:199-207.

29. Chan CS, Rhodes JE. Religious coping, posttraumatic stress, psychological distress, and posttraumatic growth among female survivors four years after Hurricane Katrina. J Trauma Stress 2013;26:257-65. 